\title{
La recepción latinoamericana del Vaticano II y la fe
}

\author{
Hugo Gudiel, S.J., \\ Centro de Reflexión Teológica
}

\section{Introducción}

Del 8 al 12 de agosto del presente año se llevó a cabo en Bogotá el encuentro anual de teólogos jesuitas de América Latina, miembros de la Comisión Teológica de la Conferencia de Provinciales Jesuitas de América Latina (CPAL). Esta pretende que sus miembros e invitados "se ayuden y se incentiven a hacer teología desde la realidad socio-eclesial latinoamericana, favoreciendo de ese modo la misión de la Compañía de Jesús en ella".

A continuación, haremos una breve exposición del encuentro de este año articulada alrededor de cinco puntos. En el primero se explican las razones para abordar el tema de la recepción latinoamericana del Concilio Vaticano II y la fe. El segundo está dedicado al Vaticano II y su indiscutible diversidad de interpretaciones. En el tercero se aborda la cuestión del pueblo de Dios y la necesaria credibilidad eclesial. El cuarto punto se centra en la cristología en el Vaticano II. $\mathrm{Y}$ el quinto punto aborda la antropología teológica en el concilio.

No pretendemos en modo alguno realizar un análisis exhaustivo de cada una de las ponencias y comunicaciones presentadas en la reunión. Nuestro objetivo es más modesto: dar a conocer a grandes rasgos unas primeras inquietudes que nos parecen fundamentales y que han surgido a partir de cada uno de los temas.

\section{De la antropología teológica a la recepción del Vaticano II}

En los encuentros de 2008 a 2010 abordamos algunas cuestiones de antropología teológica, que fueron presentadas en ponencias y comunicaciones centradas propiamente en la Antropología teológica en perspectiva latinoamericana ${ }^{1}$.

1. Sobre la síntesis del último encuentro sobre esa temática, véase H. C. Gudiel García, "Antropología teológica latinoamericana”, Carta a las Iglesias 606 (2010), 1-31 de octubre, pp. 19-21. 
En el encuentro de 2010, en Belo Horizonte, la Comisión decidió comenzar a abordar, a partir de este año 2011, algunas cuestiones en torno al Vaticano II y su recepción.

En concreto, se trata de abordar con seriedad la recepción [latinoamericana] del concilio Vaticano II en vista al reto de la transmisión de la fe ${ }^{2}$. La ocasión la brinda la proximidad de la celebración, en 2012, de los cincuenta años de la inauguración del Vaticano II en 1962, que concluyó en 1965. Y, específicamente, la necesidad de escudriñar teológicamente la praxis de recepción que dicho acontecimiento eclesial ha tenido en América Latina.

Las preguntas que a mi juicio pueden servir de hilo conductor para orientar y centrar la discusión que se tuvo y se tendrá en la Comisión Teológica durante estos años de 2011 a 2013 son las siguientes: ¿cuál es el significado e importancia eclesial y teológica de la recepción latinoamericana del Concilio Vaticano II, ante el reto de la transmisión de la fe en el contexto latinoamericano? ¿Qué significa dicho acontecimiento eclesial para la fe en América Latina, cincuenta años después de su inauguración?

Para el desarrollo de este tema fundamental, la Comisión Teológica considera que hay que prestar atención, en primer lugar, "a lo más transcendente de esta recepción en los últimos 50 años y en América Latina". Ahora bien, "lo más transcendente tiene que ver con la obra efectiva en América Latina del mismo Espíritu que inspiró el Concilio". En segundo lugar, hay que tener en cuenta que dicha "investigación se realiza en una circunstancia concreta de crisis de la transmisión de la fe de una generación a otra". La Comisión afirma que ya no se puede presuponer que la fe no impregne la cultura. Por tanto, "la investigación debe orientarse a un nuevo anuncio del Evangelio"3.

A continuación, presentamos las grandes líneas de las comunicaciones y ponencias sobre el tema, según el orden en el que fueron expuestas y debatidas.

2. Por recepción, Congar entiende aquel "proceso" en virtud del cual "un cuerpo eclesial hace verdaderamente suya una determinación que él no se ha dado a sí mismo, reconociendo en la medida promulgada una regla que conviene a su vida". Ciertamente, en la recepción hay algo totalmente distinto de la mera obediencia escolástica. En efecto, la recepción "implica un aporte propio de consentimiento, de juicio en ocasiones, expresando así la vida de un cuerpo que pone en juego recursos espirituales originales"; Y. Congar, "La recepción como realidad eclesiológica", Concilium 77 (1972), p. 58.

3. Lo cual se convierte en nuevos retos y desafíos para la misma teología latinoamericana, tal como lo hemos sintetizado a partir de P. Trigo; $c f r$. H. C. Gudiel García, “Antropología teológica latinoamericana”, óp. cit., p. 21. 


\section{El Vaticano II y la diversidad de interpretaciones}

Las primeras presentaciones estuvieron marcadas por la cuestión de la innegable diversidad, e incluso conflictividad, en las distintas interpretaciones sobre la cuestión de la recepción del Concilio Vaticano II.

\subsection{Víctor Codina: el conflicto de interpretaciones}

En esa perspectiva se inscribe, en primer lugar, el trabajo presentado por Víctor Codina: El Vaticano II en medio del conflicto de interpretaciones. Comienza reconociendo que "el Vaticano II fue una auténtica irrupción del Espíritu sobre la Iglesia, un acontecimiento salvífico, un verdadero kairós".

Entre los elementos positivos del cambio de este acontecimiento destaca los siguientes ${ }^{4}$. Ante todo, una recuperación de la eclesiología de comunión que se "abre al desafío de los nuevos signos de los tiempos" ( $(f r \text {. GS 4, 11, 44) })^{5}$. Además, la eclesiología se abre y se orienta al reino de Dios (LG 5)6. También se concibe la Iglesia como misterio, pero radicada en el misterio de la Trinidad ( $c f r$. LG 4) 7 . Asimismo, esta eclesiología es cristológica y, a la vez, pneumatológica ( $c f r$. LG 4) ${ }^{8}$.

Otro aspecto positivo consiste en que la Iglesia se entiende como corresponsable y sinodal (cfr. LG 23). Se afirma que la Iglesia es el Pueblo de Dios con diversos carismas y ministerios ( $c f r$. LG II). Es una Iglesia caminante y escatológica ( $c f r$. LG VII). Es una Iglesia servidora y evangelizadora de los pobres ( $c f r$. LG 8 , GS 1$)^{9}$. Finalmente, se afirma que la Iglesia es sacramento de salvación ( $c f r$. LG $1,9,48$ ), dialogante con otras Iglesias y religiones ( $c f r$. NA), y que reconoce la libertad religiosa ( $c f r$. DH).

4. Cfr. V. Codina, Para comprender la eclesiología desde América Latina, Navarra, 2008 (nueva edición actualizada). El mismo autor remite aquí a esta obra.

5. Sobre "los signos de nuestro tiempo", véase A. Nolan, Jesús, hoy. Una espiritualidad de libertad radical, Santander, 2007, pp. 25-78.

6. Para Ellacuría se trata de un tema central, "porque si reino de Dios no puede concebirse adecuadamente al margen de la Iglesia que ayuda a realizarlo, mucho menos puede concebirse la Iglesia al margen del reino de Dios"; I. Ellacuría, Conversión de la Iglesia al reino de Dios, San Salvador, 1984, p. 7.

7. Sobre este tema puede verse la obra de B. Forte, La Iglesia de la Trinidad, Salamanca, 1996.

8. Respecto a este último tema, véase V. Codina, "No extingáis el Espíritu" (1 Ts 5, 19). Una iniciación a la Pneumatología, Santander, 2008, concretamente las páginas 71-159. Sobre "la pneumatología del concilio Vaticano II", véase Y. Congar, El Espíritu Santo, Barcelona, 1983, pp. 195-201.

9. Aquí vale la pena considerar la obra de J. Sobrino, Resurrección de la verdadera Iglesia. Los pobres, lugar teológico de la eclesiología, Santander, 1981. 
Codina reconoce, sin embargo, que "ya el mismo Vaticano II presenta una serie de déficits que lastrarán sus elementos positivos y los ensombrecerán". Además, el mismo concilio no trató, sino que guardó silencio sobre otros "temas ya entonces candentes". En la realidad, la falta de mediaciones eclesiales no permitió la concreción y la realización de lo positivo de la eclesiología del concilio.

A esto se añade que la puesta en práctica del Vaticano II "produjo muchas reacciones y exageraciones en el seno de la Iglesia". Según Codina, "algunos sectores muy conservadores se resistieron a aceptar el Vaticano II". Pero también es cierto que de parte de otros sectores hubo "una interpretación excesivamente libre y alegre del Vaticano II", lo cual trajo críticas oficiales a su aplicación.

La conclusión es que paulatinamente "hemos ido pasando de la primavera al invierno conciliar (K. Rahner)"10. Al mismo tiempo, hay que reconocer que al final del "pontificado de Juan Pablo II hay algunos gestos de apertura" significativos. Aquí cabe notar que "los estudios históricos dirigidos por G. Alberigo han demostrado fehacientemente que el Vaticano II fue un verdadero 'acontecimiento"' 1 . Aunque, naturalmente, no todos piensan lo mismo sobre ello, pues hay opiniones opuestas.

En todo caso, Codina constata que en el actual contexto socio-eclesial ha habido como un "corrimiento de acentos y de interés en la apreciación y actualidad de los mismos documentos conciliares". Por ejemplo, de una eclesiología centrada en la constitución dogmática Lumen Gentium se pasa a acentuar el decreto Ad gentes.

Es innegable que estamos ante un "cambio de época", a las puertas de una "crisis de cultura mundial" de proporciones inéditas. De la perspectiva eclesiológica del Vaticano II, que partía de la pregunta de Pablo VI: "Iglesia, ¿qué dices de ti misma?", hemos pasado a la cuestión fundamental que el mismo Pablo VI formuló pocos años después del concilio: "Iglesia, ¿qué dices de Dios?".

En definitiva, para Codina, la Iglesia ha de "concentrarse en lo esencial, volver a Jesús y al Evangelio". Es tiempo, pues, de espiritualidad, de mística y de profecía frente al mundo de los pobres, de los excluidos, y donde la tierra aparece seriamente amenazada. Hoy toca "ir a lo esencial".

10. Del mismo V. Codina, Sentirse Iglesia en el invierno eclesial, Cuadernos Cristianisme i Justícia, Colección Eides, 46, Barcelona, 2006; puede verse también P. Imhof y H. Biallowons, La fe en tiempos de invierno. Diálogos con Karl Rahner en los últimos años de su vida, Bilbao, 1989, en concreto, las páginas 225-236.

11. El autor fundamenta esta afirmación en la obra de G. Alberigo (ed.), Historia del Concilio Vaticano II, I-V, Salamanca, 1999-2008. 


\subsection{Burgaleta y las interpretaciones del Vaticano II $^{12}$}

La segunda comunicación fue de C. M. Burgaleta (EE. UU.): Las interpretaciones del segundo concilio Vaticano. El autor expone el debate entre Avery Dulles y John W. O’Malley en $2003^{13}$, y termina enumerando algunos rasgos de la visión de Benedicto XVI. Veámoslo.

En primer lugar, según Burgaleta, Dulles hace notar que los documentos del Vaticano II fueron "productos de comités y como tales reflejan consenso que hacen la interpretación difícil”. Para evitar malas interpretaciones de la doctrina conciliar, tanto de los grupos tradicionalistas como de los progresistas, Dulles sugiere algunas normas de interpretación. Ante todo, que cada pasaje o documento del concilio "debe ser interpretado", tomando en consideración la totalidad de la "enseñanza del concilio".

Propone, además, que las cuatro constituciones principales del Vaticano II (LG, DV, SC y GS) deben ser las claves interpretativas para entender el resto de los decretos y declaraciones del concilio. Señala que "la importancia pastoral de los documentos conciliares no debe ser separada o contrapuesta a su contenido doctrinal" y que tampoco "debe oponerse el espíritu del concilio con la letra del mismo". Añade que "el concilio debe interpretarse en continuidad con la gran tradición de la Iglesia”. Y termina sugiriendo que el Vaticano II "debe aceptarse como útil para iluminar los problemas de hoy día”. En definitiva, Dulles quiere subrayar la continuidad del concilio con el pasado.

En segundo lugar, Burgaleta insiste en que la interpretación del Vaticano II de J. W. O’Malley es distinta de la de Dulles. Según O’Malley, el Concilio Vaticano II pretendía realizar "cambios fundamentales en la manera que la Iglesia funcionaba". El concilio significó una "ruptura con el pasado a pesar de su continuidad con otros concilios". Esa particularidad se "debe al estilo que propuso y que el mismo concilio encarnó para la Iglesia”.

O'Malley presenta cinco "invitaciones" de acuerdo al estilo del Vaticano II. 1. la recuperación de las tradiciones horizontales del catolicismo expresadas con claridad en la colegialidad y en la Iglesia como pueblo de Dios. 2. Servir más que controlar, persuadir más que imponer enseñanzas. 3. El cambio en la reformulación de sus afirmaciones. 4. Preferir la inclusión a la exclusión de cualquiera

12. A mi juicio, el contexto para entender la procedencia de esta ponencia se explica por lo que he expresado en otro momento: "La Comisión Teológica está compuesta por unos quince teólogos, entre los cuales hay miembros de América Latina e invitados de EE. UU. y Europa. Esto permite una riqueza insospechada en el debate teológico, tal como lo hemos constatado"; H. C. Gudiel García, "Antropología teológica latinoamericana", óp. cit., p. 19.

13. Del debate entre ambos pensadores quedó constancia en la revista América, 2003, como afirma el mismo Burgaleta. 
que desea un mundo mejor. 5. La participación activa y el compromiso, lo que queda claramente expresado en el documento sobre la reforma de la liturgia (cfr. SC). Pues bien, como puede notarse, O'Malley centra su atención en aquello que cambia, en la discontinuidad del concilio respecto de las "prácticas, enseñanzas y tradiciones anteriores".

A pesar de las diferencias interpretativas entre Dulles y O'Malley sobre el Vaticano II, Burgaleta piensa que ambos están de acuerdo en que el cambio de estilo que el concilio "introdujo fue bueno y necesario". Ambos concuerdan, además, "con las normas para interpretar el concilio propuestas por el Sínodo Extraordinario de Obispos de 1985"14.

Finalmente, Burgaleta afirma que también Benedicto XVI expresó su opinión, en $2005^{15}$, sobre el debate de la interpretación del concilio. El papa rechazó una "hermenéutica de la discontinuidad y de la ruptura" del concilio. Y propuso una hermenéutica de la "reforma que consiste en una combinación de continuidad y discontinuidad, un proceso de renovación en continuidad"16. Además, el papa "rechaza la idea de que la apertura del concilio al mundo moderno signifique el fin de la oposición entre el mundo moderno y la Iglesia".

\section{Pueblo de Dios y credibilidad eclesial}

Un segundo grupo de comunicaciones giró alrededor del pueblo de Dios y la credibilidad eclesial.

\subsection{Pedro Trigo: los cincuenta años del concilio}

Comenzamos con la primera presentación de Pedro Trigo: Hace cincuenta años empezó el Concilio.

Celebramos los cincuenta años de la inauguración del Concilio Vaticano II, dice el teólogo, "con inmensa alegría y agradecimiento". En efecto, "el concilio significó la posibilidad de vivir con coherencia nuestro cristianismo en el corazón de nuestra época". Más aún, "significó la exigencia de vivir nuestra época con responsabilidad, y la luz y la fuerza para llevarlo a cabo desde los de abajo".

14. Algunas ediciones de los documentos del Vaticano II traen, como apéndice, el texto del "Sínodo Extraordinario de 1985", aquí remitimos a los Documentos del Vaticano II, en su cuadragésima primera edición, Madrid, 1986, pp. 699-724.

15. Cfr. Benedicto XVI, "Discurso del santo padre Benedicto XVI, a los cardenales, arzobispos, obispos y prelados de la curia romana", Roma, 22 de diciembre de 2005.

16. Para explicar esta hermenéutica de reforma, Benedicto XVI se fundamenta en la manera como Juan XXIII y Pablo VI presentaron esta hermenéutica; véase ibíd., pp. 5-6. 
Trigo presenta el significado concreto del Vaticano II en las siguientes líneas maestras. Ante todo, el Cristo de nuestra fe fue adquiriendo el rostro concreto de Jesús de Nazaret. Como cristianos, desconocíamos en gran medida a Jesús de Nazaret y su Reino. Al centrar la revelación en la autocomunicación de Dios por la encarnación de su Hijo, el concilio redescubrió la Biblia, en concreto los Evangelios, como fuente de la vida cristiana y el seguimiento de Jesús ${ }^{17}$. He aquí la "buena noticia del concilio"18.

En el concilio, además, el Dios de nuestros padres adquirió el rostro del Padre de nuestro Señor Jesucristo. Jesús es quien nos ha dado a conocer a Dios como Padre suyo. En efecto, "este Padre de nuestro Señor Jesucristo es el que redescubrió el concilio a la luz de la Palabra de Dios y nos lo entregó como fuente de vida verdadera".

En el concilio, la Iglesia pasó a ser el pueblo de Dios. En otras palabras, se trata de comunidades vivas y participativas en las que los pobres juegan un papel singular. Jesús de Nazaret nos llevó a redescubrir este modo de ser Iglesia. Lo peculiar del "pueblo de Dios es llevarnos mutuamente en nuestra fe, en nuestro amor fraterno y en nuestra vida cristiana" 19 .

Partiendo de la declaración Dignitatis humanae sobre la libertad religiosa, Trigo sostiene que el concilio significó un pasar de la obediencia no deliberante a las autoridades, al derecho y al deber de seguir el dictado de la propia conciencia. Esta es la "última instancia para cada ser humano". De ahí la obligación de formarla por la investigación propia, por el diálogo con los demás y, en concreto, "por la vida de Jesús, parámetro de humanidad". En definitiva, se trata de "formar nuestra conciencia y liberar nuestra libertad".

En el Vaticano II, finalmente, se pasó de salvarse del mundo a salvarse con todos, desde los pobres. Fuera de la humanidad no hay salvación. Esa solidaridad de la Iglesia con toda la humanidad "es la buena nueva del concilio para el mundo".

Es importante notar que estas líneas maestras del Vaticano II constituyen al mismo tiempo los ejes de nuestra existencia. Baste con lo dicho para descubrir que este aniversario del concilio "es para nosotros motivo de honda celebración que nos llena de alegría y agradecimiento".

17. Las cursivas son nuestras.

18. Auque aquí Trigo no alude a ningún texto concreto del concilio, podemos remitir esta primera línea maestra a la Constitución Dogmática Dei verbum sobre la divina revelación.

19. Aquí se puede tener presente la Constitución Dogmática Lumen Gentium, en concreto LG 9-17. 


\subsection{Piedra Valdez: el Pueblo de Dios en comunión}

Destacamos ahora el trabajo de J. Piedra Valdez: Pueblo de Dios en comunión. Sobre la naturaleza de la Iglesia según el concilio Vaticano II.

En primer lugar, el autor peruano comienza mostrando la novedad que representa la Constitución Dogmática Lumen gentium (sobre la Iglesia), en el conjunto de los documentos del concilio. Para ello, parte de la evolución que se dio en la eclesiología antes del concilio, donde se trabajaron algunos modelos eclesiológicos. Entre ellos, sobresale la Iglesia como pueblo de Dios.

En ese contexto, describe detalladamente la historia de la redacción de los textos de la constitución Lumen gentium hasta llegar a la redacción final, y ubicarla en el conjunto de los documentos del concilio para explicar su desarrollo, concentrando su atención en el significado de algunos textos de la constitución ( $c f r$. LG 2, $3,10,4,9$ y 1 , respectivamente).

En segundo lugar, desde el Antiguo Testamento puede afirmarse que con la noción de Pueblo de Dios se llega a un "punto capital para la fe de Israel" (cfr. Ex 6, 6; Dt 7, 6 y Ez 11, 19-20). En el Nuevo Testamento, el pueblo de Dios es el pueblo cristiano ( $c f r$. Gal 3, 6-9). Los discípulos de Jesús tienen el "sentimiento de ser el verdadero Israel". La comunidad comienza a llamarse ecclesia de Dios, el verdadero y nuevo Pueblo de Dios. Pablo clarifica el sentido de la palabra Iglesia. En Gálatas, lo importante es la fe, no la circuncisión, mientras que en las dos cartas a los corintios de Pablo también aparece la idea de Pueblo de Dios.

En tercer lugar, Piedra aborda el significado de la categoría de comunión. Para el pueblo de Israel, la alianza es signo de comunión. Desde el Nuevo Testamento, en cambio, la Iglesia "entra en comunión con Dios por Cristo en el Espíritu Santo". Para Pablo, koinonía "explica la participación del fiel en Cristo y en la comunidad cristiana". Por una parte, "hay una comunión que nace de la cena eucarística" (cfr. 1 Co 10, 16). Por otra parte, compartir la "mesa es un signo de fraternidad en medio de los seres humanos" ( $c f r .1$ Co 11, 26). La comunión es expresión de la comunión trinitaria (cfr. 2 Co 13, 13).

La idea de comunión es "una idea directriz de la eclesiología del Concilio" (W. Kasper). El Vaticano II usa ese término en diversos sentidos: es comunión trinitaria, la Iglesia universal es comunión de iglesias locales, es comunión de fieles ${ }^{20}$.

20. En esta perspectiva, Pié-Ninot recoge una idea esencial de una obra póstuma de Zubiri en la que, entre otras cosas, expone la cuestión de la Iglesia. Ahí "puede verse también un esbozo de una eclesiología filosófica, ya que se subraya con fuerza que 'la comunidad religiosa cristiana no es primariamente una comunidad social", sino, ante todo, una "comunión de personas, una comunión personal", y esta "está fundada en la dimensión de entrega". Con "la 'eclesiología filosófica' Zubiri articula un concepto de gran densidad antropológico-filosófica: la comunión personal"”; S. Pié-Ninot, Eclesiología. La sacramentalidad de la comunidad cristiana, Salamanca, 2007, p. 241. 
Es también comunión jerárquica, es comunión ecuménica, es comunión como misión y es comunión como escatología (J. Rigal) ${ }^{21}$.

En cuarto lugar, Piedra hace un recorrido de la recepción que tanto el concepto de Pueblo de Dios como el de comunión han tenido en Latinoamérica ${ }^{22}$. Medellín y Puebla valoran la "riqueza del término Pueblo de Dios". Esos documentos apoyan las comunidades eclesiales de base. Sin embargo, la insistencia, desde 1985, en la idea de comunión vino acompañada de un "alejamiento de la idea de Pueblo de Dios". La realidad de pobreza "es un espacio para engendrar la comunión desde la periferia. Una Iglesia en comunión con los necesitados puede también ser un espacio de trascendencia”.

En definitiva, el autor considera que es posible establecer un diálogo entre las categorías Pueblo de Dios y comunión, "sin perder la riqueza que cada término aporta". En efecto, la "eclesiología de comunión no se opone a la categoría de Pueblo de Dios": entre ellas se da un mutuo enriquecimiento. Ambas "encuentran su origen en la Trinidad". Por tanto, es posible hablar de Pueblo de Dios en comunión.

Desde estas dos categorías, Piedra ha intentado definir la naturaleza de la Iglesia a la luz del concilio. En los últimos decenios ambos términos han mostrado su riqueza en el ámbito teológico, y su discusión ha estado presente en la Iglesia latinoamericana. No podemos perder la categoría de Pueblo de Dios, pero también es necesario abrirnos a la comunión. Ambas categorías tienen su raíz última en la comunión del Padre, del Hijo y del Espíritu Santo.

\subsection{Moscoso Pacheco: la credibilidad eclesial}

La comunicación presentada por A. Moscoso Pacheco versa sobre la cuestión de la necesaria Credibilidad eclesial en. $^{2}$.

De entrada, el autor boliviano advierte que la Iglesia "existe para llevar a los seres humanos hacia Jesucristo. Por eso es signo e instrumento de la salvación obrada por el Mesías" (cfr. LG 9). Y añade que "la vida de la Iglesia y la pastoral buscan hacerla efectiva aquí y ahora". Precisamente aquí es donde surge la relevancia de la cuestión sobre la "credibilidad de la Iglesia". El autor constata que en la actualidad, por diversas causas, existen contrariedades intraeclesiales

21. El autor se apoya en la obra de J. Rigal, L’Ecclésiologie de Communion, París, pp. 59-81.

22. En este contexto, puede verse I. Ellacuría, "Iglesia como Pueblo de Dios", en I. Ellacuría, Escritos Teológicos, t. II, San Salvador, pp. 317-342.

23. Sobre el tema, véase S. Pié-Ninot, "Credibilidad de la Iglesia", en C. O’Donnell y S. Pié-Ninot, Diccionario de eclesiología, Madrid, 2001, pp. 249-252. 
que afligen a algunos cristianos. Y esas contrariedades ponen en tela de juicio la credibilidad eclesial.

Según él, el problema de fondo reside en el sentimiento de Iglesia de muchos cristianos. De ahí la consecuencia: en la Iglesia "se debe poder escuchar de nuevo el mensaje de Jesús, que entusiasma, seduce y transforma el corazón del creyente". La eclesialidad es la consecuencia radical de haber experimentado a "Jesús a través de otros creyentes que, sintiéndose parte de la Iglesia, han sabido transmitirla". A Jesús se accede por el "testimonio" y la fe de los otros cristianos $^{24}$.

La Iglesia no es mera "institución", sino fundamentalmente comunión y sacramentalidad. Apoyándose en Pié-Ninot, Moscoso dice que la Iglesia tiene carácter de "signo e instrumento". Eso es lo que significa el término sacramento. Es importante insistir en que el núcleo de "la fe es Jesucristo, y que su seno materno es la Iglesia, y que esta está a su servicio como 'sacramento' suyo o ‘comunidad sacramental' de la salvación" 25 .

Sin embargo, no hay que olvidar que la Iglesia en cuanto "misterio es 'santa", pero al mismo tiempo tiene en su seno a pecadores ${ }^{26}$. Por ello necesita de arrepentimiento. De ahí que el teólogo vea la necesidad de una profunda renovación eclesial. En esta perspectiva, hay que apostar por la visión bíblica de la Iglesia como "Pueblo de Dios" del Vaticano II. No es rompiendo con la Iglesia como se realiza la novedad; eso sí, hay que "buscar modelos diferentes de realización de la misma y única Iglesia de Cristo". Considerar la diversidad de carismas y ministerios "es un camino sano en las prácticas cotidianas de las comunidades".

El autor, teniendo de fondo la carta apostólica Tertio millennio adveniente 45, de Juan Pablo II, concluye: "Situándonos en disposición de fe, podemos ver la historia, circundada y empapada por la presencia del Espíritu Santo". De esa manera, la Iglesia se siente llamada a discernir los "signos los tiempos" (GS 4). Es decir, a discernir "esos indicios significativos de la presencia y de la acción del Espíritu de Dios en la historia"27.

24. Sobre el testimonio como signo eclesial de credibilidad, véase S. Pié-Ninot, La Teología Fundamental, Salamanca, 2001, pp. 572-660.

25. Aunque el autor no remite a una obra concreta, puede ser útil la referencia a $\mathrm{S}$. Pié-Ninot, Eclesiología, óp. cit., Salamanca, 2007, pp. 213 y ss.

26. En este contexto, recuérdese el trabajo de H. U. von Balthasar, "Casta meretrix", en Sponsa Verbi, II, Madrid, 2001, pp. 197-290. También, la breve pero sugerente obra de H. de Lubac, Paradoja y misterio de la Iglesia, Salamanca, 2002, pp. 19-36.

27. Desde la teología fundamental, los signos de los tiempos "son acontecimientos históricos que crean un consenso universal, por los que el creyente es confirmado en la verificación del obrar inmutable y dramático de Dios en la historia, y el no creyente se orienta hacia la individuación de opciones cada vez más verdaderas, coherentes 


\section{Cristología y Vaticano II}

Un tercer bloque de comunicaciones giró en torno a la relación cristología y Concilio Vaticano II.

\subsection{Jorge Costadoat: la cristología en el magisterio latinoamericano}

Recordamos ante todo el trabajo de Jorge Costadoat: Recepción del Magisterio de las Conferencias episcopales latinoamericanas de la Cristología del Vaticano $I I^{28}$. Ahí ofrece una rápida selección de textos cristológicos y unas conclusiones.

Sobre Medellín, el autor concluye haciendo llamar la atención en la impronta escatológica de las referencias explícitas a los textos conciliares de carácter cristológico. Subraya también la necesidad del compromiso con la transformación de la realidad, en la perspectiva del Reino, que ya está presente, pero cuya realización definitiva está aún pendiente. Además, hay una referencia a Gaudium et spes 22 sobre la antropología cristológica ${ }^{29}$. En concreto, el misterio del hombre solo se esclarece en el misterio del Verbo encarnado: "Cristo, el nuevo Adán, en la misma revelación del misterio del Padre y de su amor, manifiesta plenamente el hombre al propio hombre y le descubre la grandeza de su vocación" (GS 22) . $^{30}$.

En Puebla, dice Costadoat, se nota el influjo de Juan Pablo II. El influjo de la cristología del concilio se deja ver a propósito del Reino de Dios. En esta conferencia predomina la visión espacial de la escatología, y se subraya la necesidad de la Iglesia para el advenimiento del Reino. Las citas principales sobre la relación Reino-Iglesia provienen de Lumen gentium (cfr. LG 5, 8) ( $c f r$. DP 226, 227). Además de lo eclesiológico, se destaca lo trinitario ( $c f r$. DP 230).

y fundamentales a favor de una promoción global de la humanidad"; R. Fisichella, "Signos de los tiempos", en R. Latourelle y R. Fisichella (ed.), S. Pié-Ninot (edición española), Diccionario de teología fundamental, Madrid, 1992, p. 1365.

Sobre el mismo tema, puede verse también I. Ellacuría, “Discernir 'el signo' de los tiempos, en Escritos teológicos, t. II, San Salvador, 2000, pp. 133-135; además, J. Sobrino, "Los 'signos de los tiempos' en la Teología de la liberación”, Estudios eclesiásticos 64 (1989), pp. 249-269.

28. Una importante tesis doctoral sobre las primeras cuatro conferencias en clave de “misión", a la luz del debate teológico y eclesial en América Latina (1995-1992) fijando su atención en algunos teólogos jesuitas, puede verse en V. Menéndez Martínez, La misión de la Iglesia, Roma, 2002, pp. 17-142.

29. Dada la importancia de Gaudium et spes 22 , he preferido colocarlo al inicio de la presentación y con mi propia selección, y no más adelante, como lo hace Costadoat.

30. Un estudio de esta cristología antropológica, según este número 22 de Gaudium et spes, en L. F. Ladaria, "El hombre a la luz de Cristo en el concilio Vaticano II", en R. Latourelle (ed.), Vaticano II: Balance y perspectivas. Veinticinco años después (1962-1987), Salamanca, 1990, pp. 705-714. 
En Puebla también aparece la relación de Cristo con las culturas. Existen "textos conciliares que sustentan la presencia de Cristo en todas las culturas" (cfr. DP 407). Esta conferencia subraya la voluntad de salvación universal que caracteriza al Vaticano II, basándose fundamentalmente en Gaudium et spes 22. Finalmente, Puebla recoge la identificación de Dios con los pobres del concilio, a propósito de su posible utilización, y citando a Juan Pablo II ( $c f r$. DP 489).

Respecto a Santo Domingo, el teólogo chileno nota que Gaudium et spes 22 también tiene especial importancia. En efecto, en virtud de la encarnación, Cristo se ha unido en cierto modo a todo ser humano. Esta conferencia subraya la relevancia que este texto cristológico del concilio tiene en el ámbito de la cultura humana, y ante un desafío evangelizador de una inculturación del Evangelio (cfr. DSD 13). La perspectiva de Santo Domingo también es histórica, y la inculturación aparece como obra de la Trinidad ( $c f r$. DSD 243). Finalmente, en esta conferencia, el Vaticano II sustenta la comprensión de la liturgia, y se la vincula con el compromiso de cambio social ( $c f r$. DSD 35).

En Aparecida, Gaudium et spes 22 vuelve a surgir como texto central (DA 107). Y sustenta la evangelización de la cultura. Sin embargo, esta conferencia constata que la cultura ha dejado de ser cristiana. Por eso, requiere de un discernimiento más sutil ( $c f r$. DA 480). Finalmente, puede verse que el influjo de lo cristológico del Vaticano II se da siempre en el ámbito de la liturgia, y esta está ubicada en un contexto apostólico amplio ( $c f r$. DA 250).

En definitiva, hay una clara y recurrente referencia a Medellín, Puebla, Santo Domingo y Aparecida, a la Constitución Pastoral Gaudium et spes 22, por lo que toca a la antropología cristológica.

\subsection{Gonzalo Zarazaga: persona y humanidad en el Hijo de Dios}

El siguiente expositor fue Gonzalo Zarazaga con su trabajo Persona y humanidad del Hijo de Dios. Aportes teológicos en torno a la persona de Jesús ${ }^{31}$.

Investiga minuciosamente el misterio de la encarnación del Verbo de Dios, impulsado por la cuestión en torno a la naturaleza humana y la persona de Jesús. La encarnación es un misterio. Es, efectivamente, el misterio central de nuestra fe que nos hace "patente" el misterio de la Trinidad.

$\mathrm{El}$ autor pretende "recapitular algunos de los aportes más destacados en torno a una vieja y fundamental pregunta cristológica: '¿Qué pensamos los cristianos cuando afirmamos en la profesión de nuestra fe que el Hijo de Dios se ha hecho

31. Se trata del trabajo ya publicado de Gonzalo Zarazaga, "Persona y humanidad del Hijo de Dios. Aportes teológicos en torno a la persona de Jesús", Estudios eclesiásticos 86 (2011), pp. 3-37. Este artículo es mucho más extenso y complejo. Dado el carácter de este trabajo, me he limitado a unas breves pinceladas. 
hombre?"'. Más en concreto, se pregunta: “QQué alcances tiene este ser hombre de Jesús el Cristo?".

A continuación, el teólogo argentino ofrece el statu quaestionis basado en el análisis de los teólogos A. Grillmeier, K. Rahner, J. H. Nicolas, W. Kasper, B. Sesboüe y P. Coda.

Afirma que en la "unidad e identidad del Hijo, del Logos económico con el Logos inmanente, se funda también la diferencia específica del hombre Jesús. Él solo se entiende a sí mismo desde su absoluta referencia a Dios, su Padre. Es esa relación la que lo define, lo sitúa e identifica. Solo en ella encuentra el hombre Jesús su propia identidad, su principio y fundamento".

El misterio de la encarnación es, precisamente, "el misterio del devenir verdaderamente hombre del Logos". Es el Logos quien sale "kenóticamente del seno del Padre para decirse como hijo en la realidad de la carne humana". El Logos inmanente "deviene mutable poniéndose-donándose como realidad humana plenamente personal".

En una de sus conclusiones, el autor advierte que "el mismo desarrollo de la cristología eclesial muestra apuntar hacia una comprensión teológica más integral, dinámica, realista y fenomenológica del misterio de la encarnación de Dios, como evento de Dios que deviene hombre en Jesús". Es tarea de la teología, sin abandonar la "verdad del dogma", profundizar en la "comprensión de la radical encarnación de Dios en la humanidad de Jesús".

La conclusión es que "el Hijo de Dios es Dios y nunca deja de ser persona divina". Es ella la que "comienza a subsistir ahora como hijo en una personalidad plenamente humana".

\section{Antropología teológica y Vaticano II}

El cuarto y último bloque de temas lo podemos ubicar en el ámbito de la antropología teológica y el Vaticano II.

\subsection{Martínez Morales: vida de humanidad, vida de Dios}

Víctor M. Martínez Morales presentó su trabajo Vida de humanidad, vida de Dios. Elementos para una antropología teológica latinoamericana.

Desde el inicio se pregunta: “Cuál será el aporte específicamente teológico que podríamos hacer cuando de aproximarnos a la humanidad se trata?". En su trabajo pretende "señalar aquellos asuntos relevantes que no pueden ser hoy desconocidos cuando nos aproximamos a una lectura teológica de lo humano". Y lo hace desde tres movimientos. 
Ante todo, propone algunas cuestiones de fondo que permitan ubicarnos en la perspectiva de toda antropología teológica. Desde ahí, las realidades del ser humano, del mundo y de Dios aparecen formando una unidad inseparable. Toda aproximación al hombre, pues, nos remite de manera directa a la realidad del mundo y de Dios. Por tanto, lo "humano, lo divino y lo terreno son elementos constitutivos del todo".

Indica, además, que se trata de acercarnos a esa antropología teológica, desde lo no-humano de la realidad latinoamericana. Es decir, desde su negación deshumanizante de pobreza, de migraciones y de nuevos escenarios y sujetos emergentes. Ese es el lugar desde el cual Dios habla hoy, y desde el que surge la pregunta: ¿cómo hacernos humanos en un contexto latinoamericano de negación de lo humano, de pobreza y de novedades emergentes?

Concluye abordando cuestiones teológicas propias de una antropología cristiana. Lo hace desde la realidad creatural, la realidad pecadora y la realidad cristológica. La antropología teológica se hace desde Jesucristo. En efecto, "nuestra antropología es cristológica. Aborda la reflexión antropológico-teológica desde lo liminal, periférico y fronterizo de la marginalidad habitada por Jesús" "32. Ahora bien, esta mirada exige una antropología de vida para la vida. Y la vida de Dios nos "viene dada en el Dios de Jesucristo".

\subsection{Pedro Trigo: la celebración del concilio como oportunidad}

Para terminar esta sección, Pedro Trigo presentó lo fundamental de su segundo trabajo: La celebración, una oportunidad para retomar el camino.

Hace cinco décadas que dio inicio el Concilio Vaticano II, y es decisivo celebrar esos cincuenta años recorridos porque "fue y sigue siendo un nuevo Pentecostés". Apelando a su propia experiencia, Trigo dice que al releer el concilio "con fe, el corazón siente, en verdad, esa frescura, ese ánimo, esa sabiduría y verdad, esa inspiración, ese reto trascendente y a la vez encarnado, que son marca de la presencia del Espíritu de Jesús de Nazaret". Celebrar este medio siglo del inicio del Vaticano II implica "hacernos cargo de lo que supuso y de lo que significa hoy para nuestra Iglesia y para nuestro mundo".

Tal celebración es expresión de gratitud y, sobre todo, de la fidelidad de los cristianos. Pero, además, la celebración puede ayudar a enfrentar las diversas dificultades vividas hoy en la Iglesia. Porque, como dice el concilio: "El porvenir de la humanidad está en manos de quienes sepan dar a las generaciones venideras razones para vivir y razones para esperar" (GS 31). Esta es la actitud del concilio y ha de ser también la nuestra.

32. En este contexto, también puede verse Gaudium et spes 22, citado anteriormente. 
A continuación, Trigo ofrece una minuciosa presentación centrada, sobre todo, en textos de Gaudium et spes que son los que le posibilitan fundamentar algunas de sus más sentidas ideas de antropología teológica. En este sentido, reconoce como novedad que, a diferencia de otros concilios, este se dirigió no solo a la Iglesia, sino a toda la "humanidad desde dentro, como formando parte de ella". Es el mismo modo de proceder del Dios de Jesús ( $c f r$. GS 40, 1 y 9).

Un aspecto de este compromiso eclesial con la humanidad "es la afirmación absoluta de todos los seres humanos por el hecho de serlo y cómo quienes afirman absolutamente a los seres humanos se constituyen en seres humanos cualitativos". Para el concilio, la humanidad corre una misma suerte, vive y tiene conciencia de una sola historia ( $c f r$. GS 33, 5, 54).

En esta época mundializada hay que afirmar el valor sagrado de todos los seres humanos. En efecto, todos los hombres y mujeres "son hermanos porque comparten el mismo origen y destino" ( $c f r$. GS 24). El origen y el fin de la humanidad están en Dios, y por eso la humanidad forma una sola familia, cuyo trato ha de ser con espíritu de fraternidad. De ahí también surge la razón de nuestra dignidad ( $c f r$. GS 19). El fundamento humano y divino de la humanidad, y de su "dignidad e igualdad, está en la persona y misión de Jesucristo" ( $c f r$. GS 10).

Pues bien, la vocación universal de la humanidad de "formar una sola comunidad, formando parte en Jesucristo de la comunidad divina [...], es la base indestructible de la dignidad de cada uno de los seres humanos y a la vez el lazo irrompible entre todos ellos". Es precisamente esta época mundializada la que posibilita y torna imperativa la afirmación de todos los seres humanos.

Además, el concilio reconoce que el ser humano tiene interioridad, vive "bajo la mirada de Dios" (GS 14). La interioridad hace al ser humano "sujeto de su destino, capaz de decidirlo". Al entrar en su interioridad, el ser humano reconoce que está ante Dios, que es fundamentalmente amor. Ese amor es la garantía de la libertad humana. "Por eso, al estar en sí, el ser humano está en su santuario: ante la presencia trascendente de Dios. Ante ella elige su destino" ( $c f r$. GS 16). Es justo la conciencia la que llama al ser humano a optar libremente por la verdad y el bien. La exigencia de formar la conciencia para buscar y seguir la verdad y el amor "libera nuestra libertad" ( $c f r$. GS 24, 17).

El hombre ha sido creado originalmente bueno por Dios. Y, sin embargo, también es cierto que el ser humano se siente inclinado al mal: toda la vida humana se manifiesta como lucha dramática entre el "bien y el mal" (GS 13). Por eso, la vida es lucha. La clave para vivir desde la propia dignidad está en el ejercicio de la sabiduría de la vida, entendida aquí como "fuerza suave y sutil hacia la verdad y el bien concretos" ( $c f r$. GS 15). Es la sabiduría la que puede liberar al hombre para la fraternidad. 
Desde el cultivo de la sabiduría, puede el ser humano no solo cultivarse a sí mismo, sino también cultivar la fraternidad, en la entrega a los demás (cfr. GS 24). Hasta aquí algunas de las ideas fundamentales de Pedro Trigo ${ }^{33}$.

\section{Conclusión}

Este encuentro de teólogos jesuitas dedicado al tema de la recepción latinoamericana del Vaticano II y la transmisión de la fe tan solo ha servido para poner sobre el tapete de la discusión cuatro cuestiones fundamentales: la diversidad de interpretaciones en torno al Vaticano II y su recepción, el pueblo de Dios y la credibilidad eclesial, la relación entre cristología y Vaticano II, y también la relación entre antropología teológica y Vaticano II.

Obviamente, son cuestiones que merecen una mayor atención y discusión. Y también son dignas de una mayor profundización, estudiándolas con más detenimiento desde la realidad eclesial y teológica de América Latina. Es una manera, no la única, de actualizar ese Espíritu del Dios de Jesús que sopló con una extraordinaria y significativa novedad hace ya cincuenta años.

Hay que volver a vivir y leer el Concilio Vaticano II desde el mismo espíritu que lo generó. Pero, al mismo tiempo, en nuestro caso es fundamental retornar a él desde este contexto y realidad latinoamericana en donde ha tenido una singular recepción. La responsabilidad de seguir historizando cristianamente lo mejor de dicho acontecimiento desde América Latina todavía está en nuestras manos.

33. El autor continúa presentando otros aspectos desde Gaudium es spes: sobre el drama de nuestro tiempo, las exigencias de la vida económica, el bien común, la organización de la política, el carácter escatológico de la humanidad y la unificación de la humanidad como oportunidad salvífica para humanizarnos por el ejercicio de la fraternidad. Pero como se podrá notar en sus últimas dos páginas, es un trabajo que no está del todo concluido y que -creemos- el teólogo terminará de perfilar en su momento. 